\title{
Ação política do empresariado industrial em processos de produção de normas ambientais no Legislativo Federal: correlação entre participação e influência
}

Eugênia Rosa Cabral *

\section{Resumo}

Restrições impostas pela regulação ambiental fazem com que instituições políticas que elaboram normas ambientais, no Brasil, tornem-se alvos de pressão do empresariado industrial. $\mathrm{O}$ estudo procura responder como participa e qual o grau de influência desse grupo de interesse em processos de configuração da política ambiental. Observou-se que o novo contexto institucional fortaleceu o sistema de representação corporativo, definiu novas formas de interação entre Estado e empresariado industrial e um novo padrão de articulação deste com o sistema político, o que o tornou um grupo de pressão influente na configuração da política ambiental. Como representantes do empresariado industrial acessam as instâncias políticas e qual a extensão de suas influências são questões analisadas à luz de teorias de grupo de interesse e abordagens institucionalistas que explicam os canais de acesso, as formas de participação e o poder de influência desse grupo, levando em conta a dinâmica das instituições alvos de pressão.

Palavras-chave: regulação ambiental, ambientalismo empresarial, articulação de interesses, pressão política.

\section{Introdução}

Estudos mostram que a incorporação da questão ambiental às agendas políticas, nacional e internacional, produziu efeitos em setores produtivos que causam significativo impacto ambiental, a exemplo do setor industrial. Segmentos desse setor incorporaram

\footnotetext{
Professora titular da Universidade da Amazônia - UNAMA e Coordenadora do Curso de Ciências Sociais. Desenvolve projeto de pesquisa com apoio financeiro da Fundação Instituto para o Desenvolvimento da Amazônia - FIDESA. Endereço eletrônico: ercabral@uol.com.br.
} 
a variável ambiental a suas agendas, reestruturando a gestão dos processos produtivos e o padrão de relacionamento com o Estado e a sociedade civil, seja em resposta às pressões políticas dos movimentos ambientalistas e de organismos internacionais, seja para se enquadrar às normas ambientais dos países onde operam (VINHA, 1999; CABRAL, 2007).

Conforme argumentam estudiosos do tema, a incorporação da questão ambiental à agenda de empresas brasileiras, especialmente aquelas que atuam no mercado internacional, aumenta a competitividade destas. Representantes do empresariado industrial, por sua vez, argumentam que a adequação às normas ambientais pode significar aumento do "Custo Brasil", que se traduz, em outros termos, na diminuição da competitividade no mercado internacional. Para estes, alguns instrumentos de regulação ambiental significam, em boa medida, excesso de regulação das atividades econômicas ou regulação ambiental excessivamente restritiva, a exemplo do licenciamento ambiental, da compensação ambiental e do seguro de responsabilidade civil por danos ambientais. Diante dessa contradição, é relevante indagar como se posiciona o empresariado industrial nos processos de produção de instrumentos da política ambiental?

Restrições impostas pela regulação ambiental fazem com que instâncias do poder público, responsáveis pela elaboração e implementação de normas ambientais, tornem-se alvos de pressão política do empresariado industrial, com vistas a influenciar nos processos deliberativos. Em função dessas restrições, a participação de representantes do empresariado industrial nos processos políticos tornou-se condição necessária para minimizar o impacto econômico da questão ambiental sobre os investimentos produtivos. Este estudo analisa a articulação de interesses do empresariado industrial, no âmbito do Legislativo Federal, em processos políticos de produção de regras ambientais, que têm como objetivo assegurar mudanças de condutas no trato com a natureza.

O objetivo do estudo é analisar em que medida o empresariado industrial é um ator político relevante no processo de configuração da política ambiental brasileira. A hipótese que orientou o estudo é de que o contexto institucional estruturado em torno da questão ambiental fortalece o sistema de representação corporativo 
e define um novo padrão de articulação de interesses deste com o Estado, o que o torna um grupo de pressão potencialmente influente na configuração da política ambiental. Como representantes do empresariado industrial acessam as instâncias políticas responsáveis pela elaboração dos instrumentos da política ambiental e qual a extensão de suas influências sobre esses processos, são questões analisadas à luz de teorias de grupo de interesse e abordagens institucionalistas próprias da Escolha Racional, que explicam os canais de acesso, as formas de participação e o poder de influência desse grupo, levando em conta a interação estratégica entre os grupos e a dinâmica de funcionamento da instituição, alvo de pressão. Procurase enfatizar a combinação da interação estratégica de indivíduos em contextos institucionais que próbem certas ações e facilitam outras, conforme a abordagem institucional de Olson (1965), North (1990) e Levi (1997).

Baseando-se na perspectiva analítica de Diniz e Boschi (2004), em estudos sobre o padrão de relacionamento do empresariado industrial com o Estado no Brasil, procura-se identificar em que medida os representantes desse grupo têm sabido explorar as oportunidades oferecidas pelo desenho institucional criado no contexto da redemocratização, pós-Constituição de 1988, para fazer valer os seus interesses. A questão que se coloca é se as formas de efetivação da pressão política do empresariado industrial são condicionadas pelas regras e dinâmica de funcionamento do sistema político brasileiro.

A análise da participação e do grau de influência do empresariado industrial sobre processos de elaboração de regras ambientais é feita a partir do estudo da participação direta e indireta de representantes do empresariado industrial no Legislativo Federal. A referência empírica deste estudo é a participação desse grupo no processo de produção de leis ambientais, mais especificamente a posição do empresariado industrial em relação a 60 projetos de leis ambientais que tramitaram no Congresso Nacional, entre 1988 e 2006, e integraram a Agenda Legislativa da Indústria (ALIN), no período de 1997 e 2006.

A perspectiva metodológica adotada neste estudo inclui procedimentos quantitativos e qualitativos visando a obter resultados 
que melhor expressassem a complexidade do problema. A partir da análise de dados e de documentos procurou-se responder às seguintes questões: qual a posição do empresariado industrial em relação aos processos de produção de regras ambientais no âmbito do Legislativo Federal? Quais foram os métodos de participação mais utilizados pelo grupo e o grau de efetividade destes? Qual foi o grau de sucesso da participação política do empresariado industrial em relação aos processos analisados? Admitindo-se que o empresariado industrial, por intermédio de suas representações políticas, mobilizou recursos para participar da produção das regras ambientais, objeto deste estudo, procurou-se mostrar se existe correlação entre o acesso, a participação e a influência desse grupo sobre os referidos processos.

\section{Participação - pressão do empresariado em processos de produção de regras ambientais no Legislativo Federal}

Com a Constituição Federal de 1988, o Congresso Nacional recuperou grande parte de seus poderes, subtraídos durante a vigência dos governos militares, além de ter ampliado o seu poder em relação à formulação de políticas públicas. Conforme assinalam Figueiredo e Limongi (1999), a nova Constituição brasileira deu ao Congresso o poder de participar efetivamente na formulação de políticas públicas, o que, somado a outras medidas, possibilitou o fortalecimento do Legislativo frente ao Executivo. Consequentemente, o Legislativo tornou-se foco de pressão dos grupos de interesse, com destaque para a atuação dos lobbies do empresariado industrial.

O empresariado industrial, por intermédio de organizações que representam os seus interesses - sobretudo a Confederação Nacional da Indústria $(\mathrm{CNI})$-, vem realizando um grande trabalho coletivo para definir e defender a posição da indústria em relação às propostas legislativas que transitam no Congresso Nacional. Com o processo de redemocratização e o fortalecimento do Legislativo como arena de negociação, a CNI se estruturou para colocar em prática ações estratégicas visando a influenciar as decisões políticas que tenham impacto direto ou indireto sobre os interesses do empresariado in- 
dustrial. Com essa perspectiva, criou a Coordenadoria de Assuntos Legislativos (COAL), que desenvolve um conjunto de atividades com o objetivo de influenciar tanto na aprovação de projetos que sejam convergentes com os interesses do empresariado industrial, quanto na rejeição daqueles que ameacem esses interesses.

Com as ações da COAL, a CNI torna público e oficial o lobby do empresariado industrial junto ao Congresso Nacional, especialmente a partir de 1996, quando passou a editar e a circular nos meios empresariais a Agenda Legislativa da Indústria. Nessa agenda são divulgadas, anualmente, as informações referentes aos vários projetos de lei em tramitação no Congresso Nacional, de interesse do empresariado industrial, com explicações detalhadas de cada projeto. Tais informações permitem que sejam identificadas as diferentes posições do empresariado industrial em relação a esses projetos. Baseando-se nesses dados e num conjunto de informações disponibilizados nos sistemas de informação da Câmara e do Senado Federal, os resultados da pesquisa mostram que, através de lobbies e da representação formal no Congresso Nacional, direta e indiretamente, o empresariado industrial participa efetivamente nos processos de elaboração de leis ambientais.

Por intermédio da ALIN, o empresariado industrial torna pública a realização de intensa ação/pressão política durante a tramitação, no Congresso Nacional, dos projetos de lei que tratam de matérias de seu interesse. Esta ação política envolve diversas atividades realizadas pelo Conselho de Assuntos Legislativos (CAL) e COAL da $\mathrm{CNI}$, classificadas em cinco categorias: acompanhamento, análise, tomada de posição, orientação e pressão. Após acompanhamento de cada passo da tramitação das matérias é feita a análise destas, tanto nos textos originais, como nas emendas, para uma tomada de posição diante de cada proposição (convergente, convergente com ressalvas, divergente e divergente com ressalvas); adotada a posição, vem a orientação dada às entidades representadas pela $\mathrm{CNI}$; por fim, desenvolve-se a pressão política, propriamente dita, ou seja, as demandas são apresentadas aos tomadores de decisão (MANCUSO, 2004, p. 516-517). O nível de organização das ações desenvolvidas pelo CAL e COAL mostra o caráter profissional do lobby desenvolvido pela $\mathrm{CNI}$, devidamente planejado e estruturado, nas várias fases de 
sua efetivação, corroborando a idéia de que lobbying não é apenas pressão, envolve um conjunto de ações complexas.

Para que os projetos convergentes com os interesses do empresariado industrial sejam aprovados ou para que os divergentes sejam rejeitados, entram em ação os agentes de pressão, que atuam "por dentro" ou "por fora" do processo de produção legislativa. De acordo com Mancuso (2004, p. 517), a pressão política em defesa dos interesses do empresariado industrial é exercida "por dentro" do processo de produção legislativa quando o contato com os tomadores de decisão se dá oficialmente. Em geral isso ocorre quando as entidades que representam os interesses do setor industrial são convidadas a participar de audiências públicas ou reuniões de trabalho e apresentar sua posição. A pressão realizada "por fora" do processo, por sua vez, ocorre nos casos em que os contatos dos agentes de pressão com os tomadores de decisão se dão por iniciativa dos representantes do empresariado industrial e não ocorrem em encontros oficiais. Ou seja, quando o grupo de pressão escolhe fazer lobby sobre membros individuais da burocracia pública ou sobre parlamentares, isolados ou em grupo, no Congresso Nacional, através de contatos diretos e informais, conforme pesquisas realizadas por estudiosos do tema (HOJNACKI \& KIMBALL, 1999; MANCUSO, 2004).

Quais são os canais de acesso do grupo de pressão às instituições, em que momento ocorre a pressão, quais são os alvos e quais são os resultados alcançados, são questões enfatizadas neste estudo. Apoiando-se na perspectiva analítica institucionalista e em evidências empíricas, considera-se que a estratégia de pressão adotada pelos representantes do empresariado industrial é fortemente determinada pelas regras do Regimento Interno da Câmara e do Senado. Isto é, que os agentes de pressão detêm conhecimento profundo das regras de funcionamento das duas casas, que os orientam na tomada de decisão em relação ao timing e ao alvo da pressão. Admite-se, a priori, que a influência só pode ocorrer sob certas circunstâncias, daí a importância da escolha do alvo da pressão (lugar ou membro do sistema político) e do momento a ser realizada, conforme assinala Hansford (2004).

Considerando que tanto na Câmara, como no Senado, de acordo com os Regimentos Internos, grande parte das proposições 
são apreciadas pelas Comissões, permanentes ou temporárias, a literatura política aponta essas Comissões como sendo o alvo de maior incidência de pressão realizada pelos grupos de pressão que atuam no âmbito do Legislativo. No âmbito das Comissões, tanto o presidente, quanto o relator podem ser o canal de acesso ou de influência direta dos grupos de pressão no processo legislativo. O que torna o presidente da comissão um alvo, em potencial, da pressão dos grupos é o controle que ele tem sobre o funcionamento dos trabalhos na comissão, desde a convocação das reuniões, a designação dos relatores, a solicitação de redistribuição da matéria a outras comissões, entre outras funções, Conforme o Art. 41 do Regimento Interno da Câmara. O relator, por sua vez, é visto como o alvo privilegiado da pressão dos grupos, não porque ele tenha poder de decisão dentro da Comissão, ou seja, que o seu parecer seja decisivo, mas, especialmente, pelo fato de o relator ser um agente informacional na comissão, visto que a ele compete: coletar, sistematizar e transmitir informações sobre as consequências de uma política pública específica, objeto da matéria em apreciação. Conforme destacam Santos e Almeida (2005, p. 701), "o relator é um ator estratégico no processo decisório intracomissão e seu poder decorre de sua função informacional ou, mais especificamente, da delegação que ele recebe da comissão para coletar e transmitir informação sobre o impacto da proposta que está relatando".

Outra instância em que pode ocorrer a pressão política dos grupos é o plenário da Câmara, do Senado ou do Congresso. Conforme Mancuso (2004), quando um dado projeto está em plenário, o foco de pressão dos representantes do empresariado industrial ou de outros grupos de pressão são os líderes dos partidos. Neste caso, os agentes de pressão agem sobre os líderes dos partidos ou das bancadas (governistas ou de oposição), a fim de garantir a aprovação ou rejeição do projeto, de acordo com os seus interesses. A importância política dos líderes de partidos e, mais precisamente, a posição privilegiada destes para influenciar nas tomadas de decisão e dinâmica dos trabalhos legislativos têm sido assunto discutido na literatura política recente (FIGUEIREDO \& LIMONGI, 1999; CINTRA \& LACOMBE, 2004).

De acordo com análises de Hansford (2004, p. 172), em relação às estratégias de lobbying de representantes de grupos de interesses 
junto a instâncias políticas, a escolha do local para ser alvo da pressão é de suma importância, visto que essa escolha pode determinar o grau de alcance das metas do grupo, ou seja, o grau de sua influência sobre a decisão política. Para o autor, quando um grupo de interesse se dispõe a participar de processos de elaboração de políticas, ele toma uma série de decisões táticas, mas este processo de tomada de decisões começa com a escolha do local, ou conjunto de locais, sobre os quais serão concentrados os esforços de lobbying.

Se o alvo de pressão dos representantes do empresariado industrial, que atuam como grupo de pressão no âmbito do Legislativo, é o relator ou o presidente das comissões, os líderes dos partidos ou de bancadas, ou ainda os membros da mesa diretora da Câmara, então, as regras que definem a dinâmica de funcionamento do poder legislativo - a divisão dos trabalhos em Comissões, a centralização de poderes dos líderes de partidos e o papel do relator nas Comissões - influenciam as estratégias adotadas pelos diversos grupos de pressão na perseguição de seus interesses. Em outras palavras, a atuação dos grupos de pressão é orientada e tornada possível pelas regras que definem a organização interna dos trabalhos legislativos. Portanto, o acesso e o grau de influência de um grupo de pressão nos processos políticos decisórios dependem, em boa medida, da disponibilidade de recursos financeiros e humanos do grupo, além do acúmulo de conhecimento do grupo sobre as regras que orientam tais processos, conforme análises desenvolvidas por cientistas políticos que estudam a ação de lobistas nos processos de elaboração de políticas (BERRY, 1984; SALISBURY, 1986; SCHLOZMAN; TIERNEY, 1986, apud FURLONG, 1997).

Há consenso entre estudiosos do tema de que grupos de interesse atribuem grande importância aos processos políticos de elaboração de leis e regras, o que explica a grande participação de diferentes grupos nesses processos, tanto na esfera do Legislativo, quanto na do Executivo. Também é consenso que as regras institucionais fornecem oportunidades aos grupos de pressão de participarem, formal e informalmente, nos processos de elaboração de políticas públicas e, possivelmente, de influenciarem as decisões, Mas, não há consenso em relação à efetividade das formas de participação e ao grau de influência dos grupos, o que pode resultar de 
Ação política do empresariado industrial em processos de produção de normas ambientais no Legislativo Federal: correlação entre participação e influência

divergências metodológicas, entre os pesquisadores, sobre como medir a efetividade dos métodos de participação usados por grupos de interesse e o grau de influência destes. Essas questões foram discutidas por Furlong e Kerwin (2005).

Este estudo fornece elementos para avaliar o grau de eficácia de grupos de pressão empresariais sobre processos legislativos. Nos itens seguintes serão apresentados os dados da pesquisa em relação ao grau de sucesso alcançado pelo empresariado industrial, por intermédio da CNI, em suas atuações no âmbito do Legislativo, referidas a proposições que tratam de temas do meio ambiente e constam nas ALIN, no período de 1997 a 2006.

\section{Natureza das proposições objetos da pressão po- lítica do empresariado industrial}

No período em estudo, foram 60 as proposições referentes à regulamentação ambiental, de interesse da indústria, que integraram o Capítulo I da ALIN, intitulado "Regulamentação da Economia", sendo $48,4 \%$ referentes a normas e padrões de qualidade ambiental; $21,7 \%$ referentes a instrumentos de zoneamento ambiental; $18,3 \%$ referentes a taxas, impostos e subsídios associados a cuidados com o meio ambiente (Quadro 1).

A partir das evidências empíricas, sistematizadas no Quadro 1 , infere-se que a grande maioria das proposições com conteúdo ambiental que figuram na ALIN é de proposições com teor normativo que se enquadram na classe de instrumentos de comando e controle $^{1}$, versando sobre normas e padrões de qualidade ambiental, zoneamento ambiental e avaliação e licenciamento ambiental (78\%). Grande parte dos temas a que se referem estas proposições é de temas que integram a chamada "Agenda Marrom" da Indústria

1 Esta definição é feita com base no disposto na Lei 6.938/81, em seu Artigo $2^{\circ}$, e modificações posteriores, que trata dos instrumentos da PNMA, amplamente usada por pesquisadores do tema. A esse respeito ver os trabalhos de Luciana T. Almeida "Política Ambiental: uma análise econômica" (1998) e "O debate internacional sobre instrumentos de política ambiental e questões para o Brasil" (1997); Margulis (1996) "A regulação ambiental: instrumentos e implementação" (1996); Floriano (2007) "Políticas de gestão ambiental". 
(resíduos sólidos; licenciamento ambiental; compensação ambiental e controle e padrões de efluentes e emissões) ${ }^{2}$. São temas que têm merecido especial atenção do empresariado industrial.

Quadro 1 - Subgrupo de Proposições em tramitação no Congresso Nacional, que figuram na Agenda Legislativa da Indústria, segundo a classe e o tipo de instrumento de Política Ambiental

\begin{tabular}{|c|c|c|c|}
\hline \multirow[t]{2}{*}{ Classes de instrumentos } & \multirow[t]{2}{*}{ Tipos de instrumentos } & \multicolumn{2}{|c|}{$\begin{array}{c}\text { № de } \\
\text { Proposições }\end{array}$} \\
\hline & & Abs. & $\%$ \\
\hline $\begin{array}{l}\text { Instrumentos voluntários ou } \\
\text { de persuasão: mecanismos com } \\
\text { caráter preventivo ou educativo. }\end{array}$ & Educação Ambiental & 02 & 3,3 \\
\hline \multirow{3}{*}{$\begin{array}{l}\text { Instrumentos de comando } \\
\text { e controle: mecanismos de } \\
\text { regulação direta, com forte } \\
\text { conotação regulatória de caráter } \\
\text { corretivo e ou punitivo. }\end{array}$} & $\begin{array}{l}\text { Normas e padrões de qualidade } \\
\text { ambiental; }\end{array}$ & 29 & 48,4 \\
\hline & \begin{tabular}{|l|} 
Zoneamento ambiental \\
(Unidades de Conservação, Área \\
de Preservação Permanente e \\
Reserva Legal); \\
\end{tabular} & 13 & 21,7 \\
\hline & $\begin{array}{l}\text { Avaliação de Impacto Ambiental } \\
\text { e Licenciamento Ambiental; }\end{array}$ & 05 & 8,3 \\
\hline $\begin{array}{l}\text { Instrumentos econômicos: } \\
\text { mecanismos com conotação } \\
\text { econômica, segundo o princípio } \\
\text { poluidor - pagador, que afetam o } \\
\text { cálculo de custos e benefícios do } \\
\text { agente poluidor. }\end{array}$ & $\begin{array}{l}\text { Incentivos à produção e } \\
\text { instalação de equipamentos } \\
\text { e criação ou absorção de } \\
\text { tecnologias, voltadas para } \\
\text { a melhoria da qualidade } \\
\text { ambiental: taxas e tarifas sobre } \\
\text { efluentes, usuário, produtos } \\
\text { e diferenciação de taxas; } \\
\text { subsídios; impostos (“imposto } \\
\text { verde”, inclusive a compensação } \\
\text { ambiental), licenças de poluição } \\
\text { comercializáveis e certificações. }\end{array}$ & 11 & 18,3 \\
\hline \multicolumn{2}{|c|}{ Total } & 60 & 100,0 \\
\hline
\end{tabular}

Fonte: Elaboração da autora a partir dos dados da ALIN, 1997-2006.

2 No Encontro Nacional de Lideranças de Meio Ambiente da Indústria, promovido pela CNI, em abril de 2006, representantes das Federações de Indústria, Conselho Temático de Meio Ambiente da CNI (COEMA), associações, institutos e diversos representantes de grandes indústrias definiram uma agenda da área de meio ambiente para atuação da CNI e demais entidades empresariais. Dessa agenda constam estratégias de atuação da representação do setor e estratégias de formulação de propostas, resultantes das discussões de três grupos de trabalho, de acordo com três agendas temáticas. (Relatório Síntese do Encontro. CNI, Brasília, junho de 2006). 
Desde 1996, a ALIN reúne, anualmente, as principais proposições legislativas em tramitação no Congresso Nacional que, se aprovadas, interfeririam na dinâmica de funcionamento das indústrias que atuam no Brasil, afetando-as positiva ou negativamente. Deduz-se que a escolha dessas proposições tenha sido determinada, exclusivamente, pelo conteúdo da ementa e que a posição do empresariado industrial varia em função desse conteúdo e não em função da autoria da proposição ou de outro fator. Ou seja, quanto mais restritivo o conteúdo, maior a probabilidade de a posição do empresariado ser divergente; quanto menor o grau de restrição, maior a probabilidade de haver convergência.

Para compreender o comportamento político do empresariado industrial no processo de produção legislativa dos instrumentos de regulação ambiental deve-se levar em conta a seguinte questão: a política ambiental brasileira ainda se baseia, quase que exclusivamente, nos princípios de comando e controle, que pressupõem o uso de instrumentos de regulação direta, com forte conotação regulatória de caráter corretivo e/ou punitivo sobre o agente poluidor. Pesquisadores da matéria têm demonstrado que, na esfera do Legislativo Federal, ainda é bastante residual a sugestão de projetos de lei ambiental visando à regular por meio de instrumentos econômicos que, em tese, dariam maior flexibilidade ao agente poluidor.

A ênfase dada pelo poder público brasileiro à regulação ambiental por meio de instrumentos de comando e controle pode ser a variável explicativa para a intensa mobilização do empresariado industrial visando a participar, direta e indiretamente, do processo de produção da legislação ambiental, tanto no âmbito do Conselho Nacional de Meio Ambiente (CONAMA) quanto na esfera do Legislativo Federal. A idéia central desenvolvida neste trabalho é de que, independente da classe do instrumento de regulação ambiental (se de "comando e controle" ou de "mercado/econômico"), os representantes do empresariado industrial participam do processo de produção dos instrumentos de regulação ambiental com o objetivo de diminuir o grau de restrição imposto por esses instrumentos, sejam eles referentes a normas e padrões de qualidade ambiental, licenciamento ambiental ou, de outra natureza, impostos ambientais, subsídios e selos ambientais. 
Os dados da pesquisa mostram a predominância da posição divergente do empresariado industrial em relação aos projetos de lei ambiental que tramitaram no Legislativo Federal, entre 1997 e 2006, com relação às proposições com maior grau de restrição, independente da classe de instrumento (Quadro 2).

Quadro 2 - Subgrupo de proposições em tramitação no Congresso Nacional, que figuram na Agenda Legislativa da Indústria, segundo o grau de restrição e a posição da Indústria

\begin{tabular}{|c|c|c|c|c|c|}
\hline \multirow[b]{2}{*}{$\begin{array}{l}\text { Grau de } \\
\text { restrição }\end{array}$} & \multicolumn{4}{|c|}{ Posição do Empresariado Industrial } & \multirow[b]{2}{*}{ Total } \\
\hline & Convergente & $\begin{array}{l}\text { Conver- } \\
\text { gente com } \\
\text { ressalvas }\end{array}$ & Divergente & $\begin{array}{r}\text { Divergente } \\
\text { com res- } \\
\text { salvas }\end{array}$ & \\
\hline \multirow[t]{2}{*}{ Menos restritivo } & 10 & 6 & 3 & 0 & 19 \\
\hline & $52,6 \%$ & $31,6 \%$ & $15,8 \%$ & & $100,0 \%$ \\
\hline \multirow[t]{2}{*}{ Mais restritivo } & 1 & 8 & 30 & 2 & 41 \\
\hline & $2,4 \%$ & $19,5 \%$ & $73,2 \%$ & $4,9 \%$ & $100,0 \%$ \\
\hline \multirow[t]{2}{*}{ Total } & 11 & 14 & 33 & 2 & 60 \\
\hline & $18,3 \%$ & $23,4 \%$ & $55,0 \%$ & $3,3 \%$ & $100,0 \%$ \\
\hline
\end{tabular}

Fonte: Elaboração da autora a partir dos dados da ALIN - 1997-2006.

Baseando-se em evidências empíricas, demonstrada no Quadro 2, com relação às 19 proposições que continham conteúdo menos restritivo, a posição adotada pelo empresariado foi mais para convergente $(84,2 \%)$ do que para divergente $(15,8 \%)$, conforme o esperado. $\mathrm{O}$ comportamento esperado se repete em relação às proposições que preconizavam maior grau de restrição: em $78 \%$ dos casos o empresariado manifestou posição de divergência, e $22 \%$ de convergência (Gráfico 1).

Conforme foi verificado, é alta a correlação entre o grau de restrição das proposições, objeto de pressão, e a posição adotada pelo empresariado industrial frente a essas proposições, o que indica qual o direcionamento do lobby efetivado pelos representantes deste segmento: se pela aprovação ou pela rejeição da referida proposição. 
Ação política do empresariado industrial em processos de produção de normas ambientais no Legislativo Federal: correlação entre participação e influência

Gráfico 1 - Grau de restrição das proposições e posição do empresariado industrial

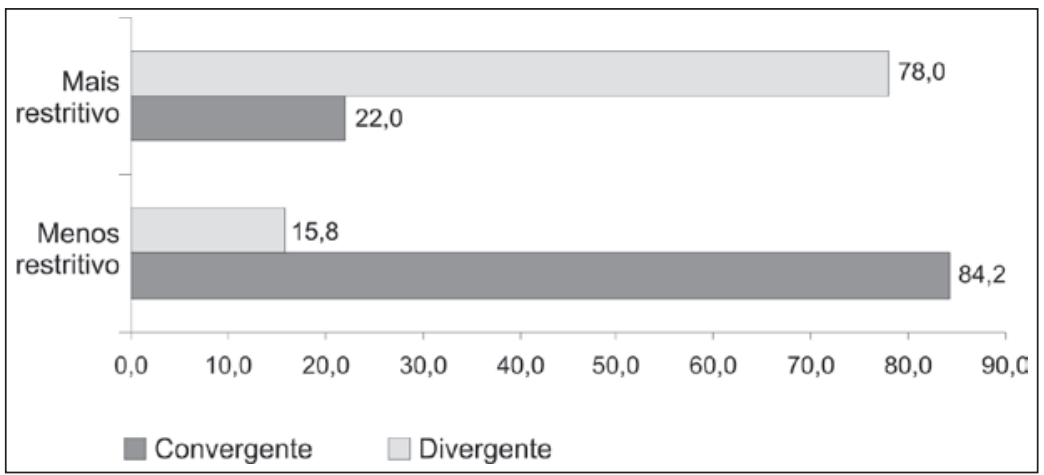

Fonte: Elaboração da autora a partir dos dados da ALIN, 1997-2006.

Nota: De acordo com resultados do teste Qui-quadrado, ao nível de 1\% de significância, há evidência de que existe relação de dependência entre as variáveis "posição do empresariado industrial" e "grau de restrição da proposição", com probabilidade de erro menor do que $1 \%$, ou seja, a um valor_p $=0,000$.

Os dados da pesquisa mostram a existência de um conjunto de temas de competência do Executivo e temas de competência do Legislativo, visto que as proposições com conteúdo que se enquadram na classe de instrumentos econômicos (subsídios, impostos, certificações e selos ambientais) são, majoritariamente, de autoria da Câmara dos Deputados, enquanto a maioria das proposições que tratam de temas referentes a zoneamento ambiental é de autoria do poder Executivo. Temas mais polêmicos, com caráter mais restritivo, que poderiam causar desgaste político ao governo, fazem parte da agenda do Legislativo, a exemplo de temas como licenciamento ambiental, seguro de responsabilidade civil por dano ambiental e análise prévia de riscos ambientais. Se essa hipótese se confirma, então é possível medir o grau de afinidades entre o empresariado industrial e os autores das proposições tomando como referência a variável conteúdo.

Com o cruzamento das variáveis "autoria versus posição do empresariado industrial" observa-se a relação existente entre autoria e conteúdo da proposição, anteriormente demonstrada, a partir da qual se pode deduzir o maior ou menor grau de afinidade dos autores das proposições com o empresariado industrial: pro- 
posições de autoria da Câmara com conteúdo mais restritivo $73 \%=$ Maior percentual de divergência e divergência com ressalvas (70,5\%); proposições de autoria do Executivo, com conteúdo mais restritivo $53,8 \%=$ Menor percentual de divergência (31\%).

Se do total de proposições apresentadas pelo Executivo observou-se um grande percentual de casos em que a posição do empresariado industrial foi convergente e convergente com ressalvas ( $15,4 \%$ e $53,8 \%$, respectivamente), então há indícios de alto grau de afinidades entre estes. Esse padrão de comportamento não se confirma quando são observados os casos em que a autoria é a Câmara dos Deputados (Gráfico 2).

Gráfico 2 - Posição do empresariado industrial em relação às proposições segundo a sua autoria

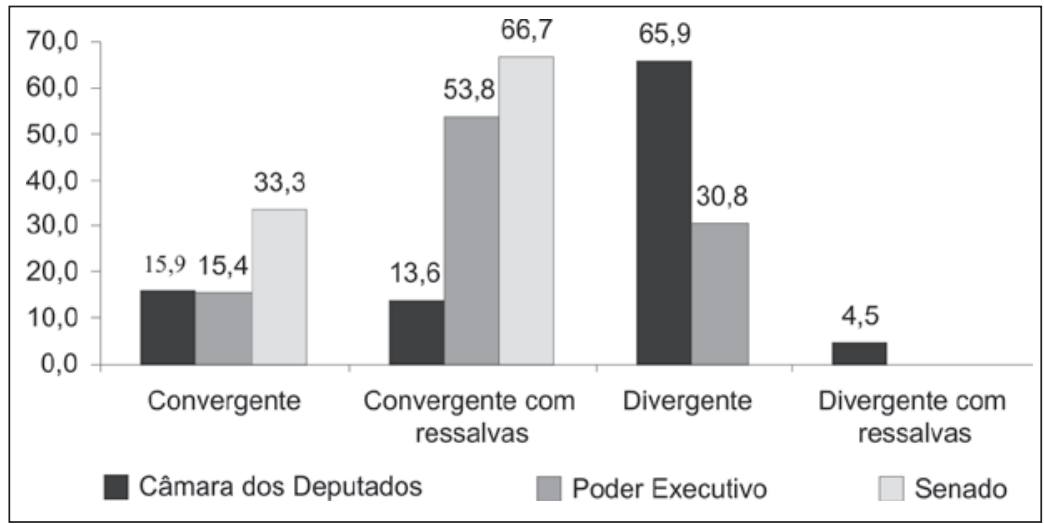

Fonte: Elaboração da autora a partir dos dados da ALIN, 1997-2006.

Nota: o teste Qui-quadrado indica um nível de significância estatística de 5\% (valor _ $\mathrm{p}=0,03)$.

Os dados mostram uma correlação alta entre o grau de restrição do projeto e a posição do empresariado industrial: menor grau de restrição $\rightarrow$ convergência, em $84 \%$ dos casos; maior grau de restrição $\rightarrow$ divergência, em $78 \%$ (Gráfico 1) . No entanto, ainda que sejam pouco representativos, visto que representam apenas $18 \%$ do total de proposições, vale mencionar a existência de casos em que essa correlação não existe. Exemplos da não-correlação podem ser vistos nas situações em que há divergência do grupo de pressão em 
relação a proposições com conteúdo menos restritivo (três casos), assim como nos casos de convergência com ressalvas em relação a proposições com conteúdo mais restritivo.

Quanto aos casos em que não há correlação positiva entre a posição do grupo e o grau de restrição da proposição, observados nas situações em que o grupo de pressão se posicionou convergente com ressalvas em relação a proposições com maior grau de restrição, observa-se um posicionamento que denota uma intenção declarada do grupo de pressão em mudar o conteúdo do projeto. Para isso, o grupo faz uso de alguns recursos, como a apresentação de emendas e de substitutivos, além de apensação de outros projetos de autoria de seus representantes, conforme se observa na tramitação de algumas das referidas proposições.

As três proposições de autoria do Executivo que não apresentam a correlação mostrada neste estudo foram os seguintes: Medida Provisória (MP) 2.166-67, de 2001, Projetos de Lei (PL) 1.616 e 7.492. Excetuando-se o PL 7.492, há evidência de que os dois outros projetos sofreram modificações ao longo de sua tramitação nas comissões permanentes, especiais e mistas, conforme destaques a seguir.

A MP 2.166-67, de 2001, trata de alterações de vários artigos e de acréscimos de dispositivos à Lei 4.771, de 1965 - Código Florestal. Alterações no Código Florestal foram feitas através de MP's, reeditadas 68 vezes entre 1996 e 2001. O processo de revisão no Código Florestal tornou-se importante alvo de pressão de representantes políticos do empresariado, em função da possibilidade de haver flexibilização nas regras em relação à utilização e exploração de florestas, ao tamanho da Reserva Legal e da Área de Preservação Permanente - um dos temas mais controversos no meio empresarial rural, desde a sua regulamentação pelo Código Florestal, conforme análises em outros estudos (CABRAL, 2007).

Em relação ao PL 1616/99, que "dispõe sobre a gestão administrativa e a organização institucional do Sistema Nacional de Gerenciamento de Recursos Hídricos", as ressalvas apresentadas pelo grupo de pressão indicavam, claramente, que o lobby seria feito no sentido de propor modificações ao projeto original, visando a adequá-lo aos seus interesses. A apresentação de emendas por parlamentares representantes do empresariado, urbano e rural, assim 
como a apensação de projetos de lei de autoria desses parlamentares ao PL em questão, foram os principais recursos utilizados pelo grupo de pressão. O principal foco das divergências do empresariado em relação a esse projeto era a definição de critérios para a cobrança pelo uso dos recursos hídricos. Portanto, esse foi o alvo da maioria das emendas de autoria dos representantes do empresariado no âmbito das comissões permanentes, o que evidencia sucesso da pressão efetivada pelo grupo de interesse, objeto deste estudo, uma vez que as emendas foram incorporadas ao projeto original.

Em relação aos projetos de lei de autoria do Legislativo que não apresentaram correlação entre as variáveis "grau de restrição" e "posição do empresariado industrial", quatro tratavam do mesmo tema (Política Nacional de Resíduos Sólidos), que tramitaram em conjunto, ao menos por um período de tempo, apensados ao PL 203/1991, que "dispõe sobre o acondicionamento, a coleta, o tratamento, o transporte e a destinação final dos resíduos de serviços de saúde". Após 14 anos de indefinição do processo, em agosto de 2005 foi instalada a Comissão Especial destinada a proferir parecer ao Projeto de Lei 203 e aos projetos a ele apensados, sendo nomeado para a presidência o deputado Benjamin Maranhão e para a vice-presidência Max Rosenmann, que é empresário e um dos integrantes da bancada ruralista na Câmara, portanto potencial aliado político do grupo de pressão.

Após sucessivos conflitos decorrentes de pouco consenso em relação a quem compete o gerenciamento dos resíduos sólidos, a destinação e a responsabilização pelos impactos ambientais, em julho de 2006 foi aprovado o parecer do relator, ressalvando os destaques apresentados, contra os votos dos deputados Luciano Zica, César Medeiros e Jamil Murad, que em suas trajetórias políticas sempre se destacaram na defesa do meio ambiente. A versão final do texto aprovado na comissão especial reflete, em boa medida, a influência do grupo de pressão, já que incorporou parte de suas demandas, contrapondo-se aos interesses dos movimentos ambientalistas, ali representados por Luciano Zica e César Medeiros.

Esses processos merecem destaque neste estudo, pois são processos políticos que mostram a capacidade do grupo de pressão de se utilizar dos recursos disponíveis, previstos regimentalmente, 
para influenciar nas decisões e tornar as proposições mais condizentes com os seus interesses. Conforme pôde ser observado, os recursos mais utilizados, na maioria dos casos, foram os seguintes: apresentação de emendas e substitutivos por parlamentares ligados à bancada empresarial da Câmara e do Senado; apensação de outros projetos de lei ao projeto em apreciação, de autoria de parlamentares da bancada empresarial; pedido de redistribuição do processo, para que este fosse apreciado em instâncias políticas que apresentassem maior grau de congruência entre os interesses empresariais e os interesses dos tomadores de decisão. A pesquisa mostra evidências de que os pedidos de redistribuição de processos, na maioria das vezes, refletem a atuação de grupos de pressão junto às instâncias políticas que apresentam maior receptividade aos seus interesses.

Conforme análises desenvolvidas por Hansford (2004, p.175), o grau de congruência entre os interesses da instância decisória alvo do lobby e os interesses do grupo de pressão política, pode ser avaliado tomando como referência dois fatores: a posição política de cada lado e a agenda política desta instância. Para este autor, quanto mais próxima a posição política dominante na esfera deliberativa com a posição defendida pelo grupo de interesse, mais provável é a escolha desse lugar como alvo do lobby; quanto maior o espaço que aquele lugar aloca em sua agenda para a questão que preocupa o interesse organizado, maior é a probabilidade de o grupo de interesse o escolher como o lugar ideal para fazer lobby em defesa de seus interesses.

Por conseguinte, a escolha de uma dada comissão para ser alvo do lobby de grupos de interesse, no âmbito do Congresso Nacional, depende do grau de receptividade que aquela instância política oferece à posição defendida pelo grupo de pressão, visto que a influência tem maior probabilidade de ocorrer sob certas condições favoráveis aos interesses daquele grupo. E, se tais condições estão relacionadas à agenda política daquela esfera decisória e à posição política do conjunto de seus membros ou de atores estratégicos, a exemplo do relator e presidente da comissão, então é provável que os pedidos de redistribuição dos projetos de uma comissão não-receptiva ou com receptividade moderada aos interesses de grupos de pressão 
para outra que apresente maior grau de receptividade, sejam resultantes da atividade do lobbying empresarial. Esse é, pois, um tipo de recurso, previsto regimentalmente, que facilita a participação, formal e informal, dos grupos de pressão em instâncias políticas onde a probabilidade de haver sucesso na influência é maior.

Em síntese, se existe a possibilidade de redistribuição de um projeto de lei de uma comissão menos receptiva aos interesses do grupo de pressão para outra, então a melhor estratégia a ser usada pelo grupo de pressão é solicitar a sua redistribuição à mesa diretora ou ao presidente daquela comissão que apresente maior grau de receptividade aos seus interesses, em vez de o grupo investir recursos em lobbying em ambientes políticos que sejam menos favoráveis aos seus interesses. Os dados da pesquisa mostram a habilidade de os representantes do empresariado industrial fazerem uso desse recurso.

Vale mencionar que as proposições que interessavam ao empresariado industrial foram apresentadas à Mesa da Câmara, em sua maioria, entre 1995 e 2005 (86,7\% das 60 proposições), período que corresponde ao exercício das $50^{\mathrm{a}}$, $51^{\mathrm{a}}$ e $52^{\mathrm{a}}$ Legislaturas. Trata-se de um contexto político marcado por fortes pressões dos movimentos ambientalistas, nacionais e internacionais, sobre o sistema político brasileiro. A meta era garantir maior regulação ambiental, em cumprimento de acordos firmados por ocasião das duas últimas conferências internacionais sobre o meio ambiente (Rio-92 e Rio +10). É, portanto, um período em que os representantes políticos deveriam elaborar a agenda ambiental brasileira ("Agenda 21"), para enfrentar os problemas ambientais agravados no último milênio.

Embora não se proponha uma análise de cada projeto de lei, em sua especificidade, cinco casos que figuraram na ALIN em até 8 vezes são bastante ilustrativos para este estudo, não obstante representem menos de $10 \%$ do total de proposições estudadas. Tais projetos pressupunham maior grau de restrição ao uso dos recursos naturais. Em função disso, o grupo de pressão se posicionou divergente na maioria dos casos, as proposições foram arquivadas ao final do processo de tramitação ou encontram-se "esquecidas", embora prontas para inclusão na pauta para votação pelo plenário. Isso mostra a influência do grupo de pressão no processo de regu- 
lamentação de assuntos polêmicos de seu interesse. Um dos casos mais emblemáticos refere-se ao Projeto de Lei 4.558/98. Esse é um exemplo da não-efetivação da produção legislativa, no que se refere ao tema em questão, sob a pressão efetiva dos grupos de interesse, desfavoráveis à matéria. Dado o caráter polêmico da matéria objeto da proposição (criação de selo ambiental para embalagens), o tempo de tramitação ultrapassou 8 anos, entre as duas últimas legislaturas (51모 e $\left.52^{\underline{a}}\right)$ e após ter sido apreciado em três comissões permanentes da Câmara o processo foi arquivado.

Outro caso de pressão dos representantes do empresariado industrial, em longo prazo, refere-se ao Projeto de Lei 710/88, que se propõe disciplinar o estudo de impacto ambiental (EIA). Trata da obrigatoriedade de EIA e respectivo Relatório de Impacto Ambiental (EIA/RIMA) em casos de atividades potencialmente causadoras de degradação ambiental, um dos temas mais controversos no campo da política ambiental brasileira. Em função disso, o tempo de tramitação desse projeto chegou a quase 15 anos, tendo sido arquivado após tramitação em todas as instâncias competentes. Neste caso, a atuação do grupo de pressão pela não-aprovação da proposição e sua transformação em norma jurídica contou com a atuação de membros do sistema político, que são absolutamente contrários a uma regulação da matéria, na forma de lei. De acordo com a opinião de parlamentares, de membros da burocracia pública e de diversos segmentos empresariais, conforme depoimentos veiculados pela imprensa nacional e pesquisas realizadas pela $\mathrm{CNI}^{3}$, a forma como vem sendo regulamentada a obrigatoriedade do EIA-RIMA “já é além

3 Além de manifestações contrárias do empresariado em relação à obrigatoriedade de licenciamento ambiental e elaboração de EIA-RIMA, importantes setores do Governo defendem publicamente a flexibilização das regras que tornam obrigatória a Avaliação de Impacto Ambiental (AIA) e a elaboração de EIA-RIMA. Em abril de 2007, tornou-se público o anteprojeto de lei de autoria do diretor-geral da Agência Nacional de Energia Elétrica (ANEEL), que propõe o fim do licenciamento ambiental para projetos do setor energético, especialmente hidrelétricas, considerados prioridades nacionais. Segundo o autor, o presidente da República se tornaria responsável por selecionar as obras de energia que atenderiam às necessidades do país. A exigência de licenciamento ambiental deixaria de existir por meio de um decreto presidencial. Disponível em: < http://www.cartamaior. com.br/templates/materia > . Acesso em julho de 2007. 
do desejável". Há, portanto, evidências de afinidades de interesses entre representantes do empresariado industrial e instâncias de decisão política, tanto no Executivo quanto no Legislativo, quando o assunto gira em torno da obrigatoriedade do licenciamento ambiental, entendido como elemento de restrição ao crescimento econômico, o que facilita, em boa medida, o lobby contrário do grupo de pressão.

Esses casos merecem referência neste estudo porque demonstram o poder de articulação e a persistência do grupo de pressão em acompanhar, sistematicamente, ao longo de vários anos, a evolução das discussões dos referidos projetos de lei em tramitação. Cabe agora analisar o grau de sucesso da pressão político do grupo de interesse objeto deste estudo.

\section{Grau de sucesso da pressão política: correlação entre acesso, participação e influência do empre- sariado industrial}

Um grande número de estudos mostra que é grande a participação de representantes de interesses empresariais nos processos de elaboração de leis, na esfera do Legislativo. Mas, não existe consenso entre os estudiosos do tema, sobre o grau de influência dos grupos de interesse sobre os resultados da política, ou seja, se a influência é proporcional à dimensão da participação de tais grupos, conforme enfatizam Furlong e Kerwin (2004). De acordo com estes autores, muitos pesquisadores têm grande dificuldade de lidar com o problema de como medir a influência de grupos de interesse sobre processos políticos governamentais. Alguns estudiosos simplesmente admitem que acesso é igual à influência, portanto assumem, em suas análises, que a influência de um grupo é baseada no grau de acesso que este grupo tem às esferas do poder público (SCHLOZMAN \& TIERNEY, 1986 apud FURLONG, 1997; HANSEN, 1991 apud BOUWEN, 2001). Bouwen (2001), por sua vez, procura mostrar que acesso não necessariamente significa influência, visto que alguns grupos de interesse podem ter acesso às instâncias políticas, mas não conseguem transformar este acesso em resultados políticos concretos de acordo com os seus interesses. Este autor 
admite, no entanto, que o acesso é condição necessária para que se possa exercitar a influência nos processos de elaboração de política. Nesse sentido, o acesso é um indicador de influência.

Não resta dúvida de que os representantes do empresariado industrial tiveram acesso às instâncias políticas por onde tramitaram os projetos de leis ambientais, objeto do estudo. Existem evidências da influência desse grupo, assim como existem evidências de que o acesso nem sempre significou influência, ou seja, o lobby não teve sucesso. As situações de insucesso do grupo de pressão, embora residuais, merecem referência neste estudo, pois mostram que o acesso de grupos de pressão com grande poder, tal qual o empresariado industrial, visto que detém recursos financeiros e humanos, além de habilidades para transformar estes recursos em resultados políticos concretos, nem sempre significa influência. Além disso, tais casos merecem destaque pelo fato de terem ocorrido em várias arenas políticas, a exemplo das comissões, o que mostra que, circunstancialmente, nem sempre a posição defendida pelo grupo de pressão encontra maior receptividade nas comissões onde o grau de afinidade de interesses é dado pelo conteúdo da agenda da comissão e a posição política dos relatores. Esses casos ocorreram em seis das 15 comissões por onde tramitaram as proposições analisadas neste estudo.

O sucesso ou insucesso da pressão política no processo de produção legislativa, além de estar relacionado à aprovação ou rejeição de uma proposição, pode ser resultante de um outro tipo de comportamento adotado pelos atores políticos, tanto no âmbito das comissões, como no plenário, quando este é o alvo da pressão. Este outro tipo de reação, convergente ou divergente em relação à posição adotada pelo grupo de pressão, pode ser a apresentação de emendas à proposição em tramitação. A apresentação de emendas no âmbito das comissões ou no plenário pode ser vista como um comportamento influenciado pela atuação do grupo de pressão, especialmente as emendas com teor modificativo ou substitutivo.

O resultado final do processo de produção legislativa, observado em relação ao conjunto de proposições objeto deste estudo, de acordo com a metodologia adotada, é considerado como variável dependente. Em função do tipo de limitações explicativas que estão 
na base do argumento causal, deve esclarecer-se que a pesquisa identifica o grau de sucesso do grupo de pressão, relacionando-o ao resultado final do processo legislativo. Mas isso não permite concluir que determinado tipo de resultado tenha ocorrido exclusiva ou predominantemente por causa da influência política do empresariado industrial, que atuou como grupo de pressão, ao longo do processo legislativo 4 .

Para efeito deste estudo foram identificados quatro tipos de resultado final no processo de produção legislativa, que encerram a tramitação do conjunto de proposições legislativas, em relação às quais o empresariado industrial se posicionou, a saber: transformação em norma jurídica; rejeição ou arquivamento ao final da legislatura; tramitação em conjunto; no plenário, pronto para pauta. No segundo tipo estão inclú́dos os casos em que o arquivamento da proposição decorreu de rejeição, de não-manifestação das comissões no prazo regimental ou de retirada pelo autor (Artigos 58, 105 e 133, do Regimento Interno) ${ }^{5}$.

Nas situações em que o resultado final foi o arquivamento, ou por rejeição, ou por retirada pelo autor, ou por decurso de prazo regimental, a pesquisa não dá elementos para que se possa afirmar que o lobby contrário do grupo de pressão (nos casos em que a posição adotada pelo empresariado industrial foi "divergente" ou "divergente com ressalvas") determinou tal resultado - situação que se configuraria como sucesso do grupo de pressão. Nenhum dos tipos de resultado, observados ao final do processo legislativo, pode ser explicado de modo conclusivo como consequência da atuação do grupo de pressão. Ou seja, conforme afirmativa de Mancuso: "em nenhuma circunstância as informações produzidas autorizam o raciocínio contrafactual de que os sucessos políticos da indústria

4 Considera-se que a base de todo argumento causal é o raciocínio contrafactual (KING et al, 1994, apud MANCUSO, 2004). Portanto, utilizar-se deste raciocínio significa afirmar que a influência de um ator $X$ é a causa de uma decisão observada Y. Isso significa afirmar, em certa medida, que a decisão Y não decorreu de outros fatores e que, por conseguinte, sem a existência da influência de X, ela não teria ocorrido.

5 As situações de arquivamento das proposições aqui estudadas são aquelas previstas nos seguintes artigos do Regimento Interno da Câmara: Art. 58, Art. 105 e Art. 133. 
não teriam ocorrido caso esta não tivesse realizado o lobby, seja ele defensivo ou ofensivo" (2004, p.523).

Conforme se vê no Quadro 3, as situações de sucesso e insucesso da pressão política do empresariado industrial são avaliadas em função do resultado alcançado ao final do processo legislativo. No entanto, conforme assinalado anteriormente, os dados da pesquisa não permitem que se estabeleça uma relação de causalidade entre a posição do grupo de pressão (variável "x") e o resultado final do processo (variável " $y$ ”). O grau de sucesso e de insucesso do grupo de pressão é avaliado por comparação da posição desejada por este com o resultado final do processo de tramitação das proposições escolhidas para integrar a ALIN, nos últimos dez anos. Em síntese, o que se quer ressaltar é que há atuação do grupo de pressão no processo de produção da regulação ambiental que se efetiva na esfera do Legislativo Federal, na maioria das vezes defendendo posição contrária à transformação das proposições em norma jurídica.

Quadro 3 - Critérios utilizados para classificar os resultados como Sucesso ou Insucesso da Pressão Política do Empresariado Industrial.

\begin{tabular}{|c|c|c|}
\hline $\begin{array}{l}\text { Decisão / Resultado } \\
\text { Final (y) }\end{array}$ & $\begin{array}{l}\text { Posição da CNI adotada na } \\
\text { última Agenda Legislativa }(\mathbf{x})\end{array}$ & $\begin{array}{c}\text { Resultado da } \\
\text { pressão política }(\mathrm{z})\end{array}$ \\
\hline Norma Jurídica & $\begin{array}{l}\text { Convergente e Convergente } \\
\text { com ressalvas }\end{array}$ & Sucesso \\
\hline Norma Jurídica & $\begin{array}{l}\text { Divergente e Divergente com } \\
\text { ressalvas }\end{array}$ & Insucesso \\
\hline Arquivamento & $\begin{array}{l}\text { Divergente e Divergente com } \\
\text { ressalvas }\end{array}$ & Sucesso \\
\hline Arquivamento & $\begin{array}{l}\text { Convergente e Convergente } \\
\text { com ressalvas }\end{array}$ & Insucesso \\
\hline Tramitando em Conjunto & $\begin{array}{l}\text { Convergente e Convergente } \\
\text { com ressalvas }\end{array}$ & Sucesso \\
\hline Tramitando em Conjunto & $\begin{array}{l}\text { Divergente e Divergente com } \\
\text { ressalvas }\end{array}$ & Insucesso \\
\hline Plenário, pronto pra pauta & $\begin{array}{l}\text { Convergente e Convergente } \\
\text { com ressalvas }\end{array}$ & Sucesso \\
\hline Plenário, pronto pra pauta & $\begin{array}{l}\text { Divergente e Divergente com } \\
\text { ressalvas }\end{array}$ & Insucesso \\
\hline
\end{tabular}

Fonte: Elaboração da autora, adaptado do modelo adotado por Mancuso (2004: 520). 
Ao final do processo de tramitação das 60 proposições que figuraram na ALIN, entre 1997 e 2006, no capítulo reservado ao tema meio ambiente, os resultados foram os seguintes: $70 \%$ foram arquivadas, em função de rejeição, decurso de prazo e retirada pelo autor; $18,3 \%$ continuam tramitando no Congresso Nacional; $6,7 \%$ estão no plenário, prontas para pauta; $5 \%$ transformaram-se em normas jurídicas. (Quadro 4). Os três projetos transformados em normas jurídicas foram o PL 3.792/93 (Lei 9.795, de 1999 - Política Nacional de Educação Ambiental), o PL 2.892/92 (Lei 9.985, de 2000 - Lei do Sistema Nacional de Unidade de Conservação) e o PL 3.285/92 (Lei 11.428/2006 - Lei da Mata Atlântica).

Quadro 4 - Resultado final do processo de tramitação das proposições e posição do empresariado industrial em relação a elas

\begin{tabular}{|c|c|c|c|c|c|}
\hline \multirow{2}{*}{$\begin{array}{l}\text { Posição do } \\
\text { Empresariado } \\
\text { Industrial }\end{array}$} & \multicolumn{4}{|c|}{ Resultado final do processo de tramitação } & \multirow[b]{2}{*}{ Total } \\
\hline & $\begin{array}{l}\text { Norma } \\
\text { jurídica }\end{array}$ & $\begin{array}{l}\text { Rejeitado / } \\
\text { Arquivado }\end{array}$ & $\begin{array}{l}\text { Tramitando } \\
\text { em conjunto }\end{array}$ & $\begin{array}{c}\text { Plenário, pronto } \\
\text { para pauta }\end{array}$ & \\
\hline Convergente & 01 & 06 & 03 & - & 10 \\
\hline $\begin{array}{l}\text { Convergente } \\
\text { com ressalvas }\end{array}$ & - & 08 & 04 & 03 & 15 \\
\hline Divergente & 02 & 28 & 03 & - & 33 \\
\hline $\begin{array}{l}\text { Divergente } \\
\text { com ressalvas }\end{array}$ & - & - & 01 & 01 & 02 \\
\hline Total & 03 & 42 & 11 & 04 & 60 \\
\hline$\%$ & 5,0 & 70,0 & 18,3 & 6,7 & 100,0 \\
\hline
\end{tabular}

Fonte: Elaboração da autora a partir dos dados do Site da Câmara dos Deputados e da ALIN (1997-2006).

Com base nos dados do Quadro 4 pode-se construir uma síntese do significado dos resultados finais para o grupo de pressão, em termos de sucesso e insucesso, tomando como referência temporal o final da 52a ${ }^{\underline{a}}$ Legislatura (Quadro 5).

Considerando-se o conjunto de todas as proposições acompanhadas e de acordo com os critérios adotados neste estudo para classificar as situações de sucesso e de insucesso da pressão política 
do empresariado industrial, verifica-se que há mais sucesso do que insucesso. Entretanto, se a referência de análise são os casos em que houve a transformação da proposição em norma jurídica, a despeito da pressão política contrária do grupo de pressão, então o percentual de insucesso $(66,7 \%)$ é maior do que o percentual de sucesso $(33,3 \%)$. Deve enfatizar-se que tal conclusão vale apenas quando se leva em conta o tipo de resultado final. Nos demais tipos de resultado, as situações de sucesso são sempre mais frequentes.

Quadro 5 - Resultado final do processo, posição do empresariado industrial e resultados da pressão política (\%)

\begin{tabular}{|c|c|c|c|}
\hline \multirow{2}{*}{$\begin{array}{l}\text { Resultado Final } \\
\text { do processo }\end{array}$} & \multirow{2}{*}{$\begin{array}{l}\text { Posição do } \\
\text { Empresariado Industrial }\end{array}$} & \multicolumn{2}{|c|}{ Resultado da Pressão } \\
\hline & & Esperado & $\begin{array}{c}\text { \% de } \\
\text { Alcançados }\end{array}$ \\
\hline Norma Jurídica & $\begin{array}{l}\text { Convergente e Conver- } \\
\text { gente com ressalvas }\end{array}$ & Sucesso & $33,3 \%$ \\
\hline Norma Jurídica & $\begin{array}{l}\text { Divergente e divergente } \\
\text { com ressalvas }\end{array}$ & Insucesso & $66,7 \%$ \\
\hline Arquivamento & $\begin{array}{l}\text { Divergente e Divergente } \\
\text { com ressalvas }\end{array}$ & Sucesso & $66,7 \%$ \\
\hline Arquivamento & Convergente & Insucesso & $14,3 \%$ \\
\hline Arquivamento & $\begin{array}{l}\text { Convergente com res- } \\
\text { salvas }\end{array}$ & Insucesso & $19,0 \%$ \\
\hline Tramitando em conjunto & Convergente & Sucesso & $27,3 \%$ \\
\hline Tramitando em conjunto & $\begin{array}{l}\text { Convergente com res- } \\
\text { salvas }\end{array}$ & Sucesso & $36,4 \%$ \\
\hline Tramitando em conjunto & Divergente & Insucesso & $27,3 \%$ \\
\hline Tramitando em conjunto & Divergente com ressalvas & Insucesso & $9,0 \%$ \\
\hline Plenário, pronto para pauta & $\begin{array}{l}\text { Convergente com res- } \\
\text { salvas }\end{array}$ & Sucesso & $75,0 \%$ \\
\hline Plenário, pronto para pauta & Divergente com ressalvas & Insucesso & $25,0 \%$ \\
\hline
\end{tabular}

Fonte: Elaboração da autora a partir dos dados do Site da Câmara dos Deputados e da ALIN (1997-2006).

Os casos de sucesso do grupo de pressão, conforme se vê no Quadro 6 e Gráfico 4, são frequientes nas situações em que o resul- 
tado final do processo de produção legislativa foi o arquivamento da proposição $(66,7 \%)$, ou seja, nas situações em que o grupo de pressão atuou contra a aprovação da proposição (lobby contrário do grupo de pressão). São frequentes, também, as situações de sucesso do grupo de pressão quando a sua atuação foi favorável à proposição: $75 \%$ dos casos em que as proposições se encontram no plenário, aguardando inclusão na pauta de votação; $64 \%$ dos casos em que a proposição continua tramitando no Congresso Nacional. Embora o resultado final seja ainda bastante indefinido, esses casos representam relativo sucesso, especialmente pelo fato de o processo de tramitação não ter culminado em arquivamento.

Gráfico 4 - Percentual de casos de sucesso e insucesso do grupo de pressão em relação ao resultado final do processo de tramitação das proposições que figuram na ALIN, 1997-2006

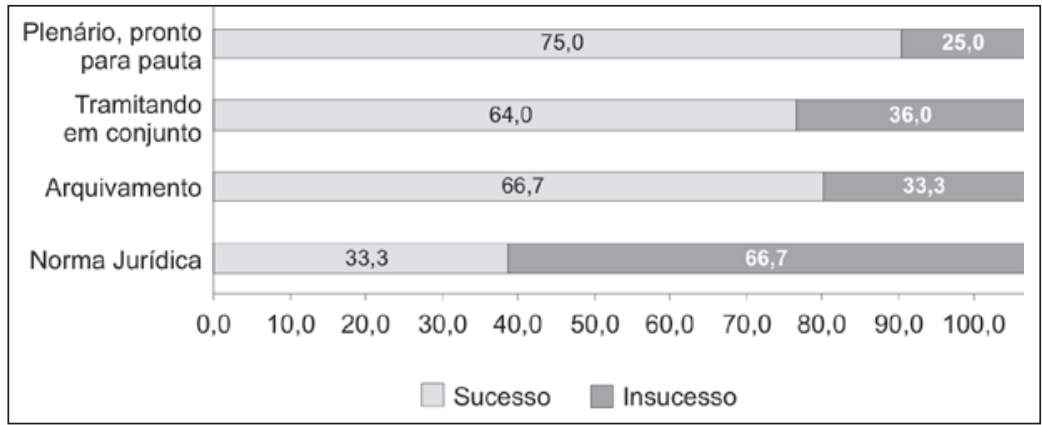

Fonte: Elaboração da autora a partir dos dados do Site da Câmara dos Deputados e da ALIN (1997-2006).

Em síntese, o saldo líquido da atuação do grupo de pressão foi positivo, visto que em $65 \%$ dos casos, o resultado final significou sucesso do lobby da $\mathrm{CNI}$, que é a principal representante dos interesses do empresariado industrial na esfera legislativa federal.

Entre os casos de insucesso do grupo de pressão, que somam $35 \%$ do total de casos observados, merece referência neste estudo, a título de ilustração de lobbying parcialmente neutralizado, o processo de tramitação do PL 3.285 de 1992, que dispõe sobre a utilização e proteção do Bioma Mata Atlântica, transformado em norma jurídica, após 14 anos de tramitação no Congresso Nacio- 
Ação política do empresariado industrial em processos de produção de normas ambientais no Legislativo Federal: correlação entre participação e influência

nal, sob a pressão permanente de representantes do empresariado industrial e de outros setores produtivos.

\section{Considerações Finais}

$O$ forte interesse do empresariado industrial em diminuir o grau de restrição dos instrumentos de regulação ambiental, em relação ao uso econômico dos recursos naturais e em relação aos cuidados com o meio ambiente (controle de poluição, por exemplo), visando a diminuir os custos com os investimentos ambientais, é um fator que, associado à disponibilidade de recursos financeiros e humanos pelo grupo, explica sua destacada participação nos processos legislativos analisados. A participação efetiva de representantes dos interesses empresariais (parlamentares e lobistas) nos processos analisados reflete, em grande medida, a capacidade de mobilização política desse grupo, o que expressa um alto grau de coesão do grupo em relação à questão ambiental, a despeito das diferenças internas do setor.

Este estudo procurou mostrar, a partir de experiências concretas, como o empresariado industrial se articula para que seus interesses influenciem as deliberações políticas concernentes à regulação ambiental e, às vezes, é bem sucedido. Os resultados da pesquisa mostram que, em um contexto político-institucional democrático, a pressão política dos grupos de interesse pode traduzir-se em sucesso ou insucesso. Essas situações podem ocorrer independentemente dos recursos de poder à disposição do grupo de interesse.

Confirmou-se a hipótese de que o novo contexto políticoinstitucional fortaleceu o sistema de representação corporativo e, ao mesmo tempo, definiu novas formas de articulação do empresariado industrial junto ao Estado, o que potencializou o seu poder de influência nas decisões concernentes à política ambiental. São evidências empíricas que contrariam as teses da debilidade política do empresariado industrial no Brasil, pois mostram que o processo de regulação ambiental, ao impor restrições às atividades produtivas, provocou uma maior agregação desse grupo e o induziu a uma organização política mais sistemática, de forma a participar efetivamente junto às instituições políticas com vistas a influenciar nas decisões. 
Os resultados deste estudo destacam a importância de condicionantes institucionais que potencializam a incorporação de interesses de grupos na formulação de políticas públicas, ressaltando a proeminência dos atores estatais. A despeito das situações que se traduzem em insucesso da pressão política do empresariado industrial, os dados da pesquisa mostram que esse grupo tem sido influente nas decisões concernentes à política ambiental brasileira. Seu poder de articulação política com o Estado explica, em boa medida, as situações de sucesso da pressão, exercida na esfera do Legislativo Federal.

Recebido em: 29.7.2010

Aprovado em: 09.9.2010

\section{Referências}

AVELAR, L. Participação política. In: AVELAR, L. \& CINTRA, A.O. (Orgs.). Sistema político brasileiro: uma introdução. Rio de Janeiro: Fundação Konrad - Adenauer-Stiftung, 2004.

BOUWEN, P. Exchanging access goods for access: a comparative study of business lobbying in the EU institutions. Forthcoming, European Journal of Political Research, 2004. Disponível em: $\leq$ http:// www.coll.mpg.de/pdf_dat/EJPR-Bouwen-2004.pdf $>$. Acesso em 02/07/2007.

. Corporate lobbying in the European Union: towards a theory of access. European University Institute, Florence. Paper provided by European University Institute, Political and Social Sciences, in its series Papers n. 2001/5. Disponível em: <http://www. iue.it/PUB/sps20015.pdf> . Acesso em julho/2007.

BRAGA, T. Meio ambiente e grandes empresas: otimismo do discurso, pessimismo da ação. Anais do VII Seminário sobre a economia mineira. Belo Horizonte: CEDEPLAR/UFMG, 1995.

CABRAL, E.R. Articulação de interesses do empresariado industrial no processo de produção da regulação ambiental: convergências e divergências. Belo Horizonte. Tese (Doutorado em Ciências Humanas: sociologia e política). Universidade Federal de Minas Gerais, 2007. 
Ação política do empresariado industrial em processos de produção de normas ambientais no Legislativo Federal: correlação entre participação e influência

. Institucionalização da questão ambiental e exploração mineral no Pará e Minas Gerais: valorização da natureza e inversão da imagem da mineração? Revista Iberoamericana de Economía Ecológica - REDIBEC, Quito - Ecuador, v. 5, diciembre 2006. Disponível em: < http://www.redibec.org/> . Acesso em jan/2007.

CINTRA, A.O. O sistema de governo no Brasil. In: AVELAR, L. \& CINTRA, A.O. (Orgs.). Sistema político brasileiro. Rio de Janeiro: Fundação Konrad - Adenauer-Stiftung, 2004.

CONFEDERAÇÃO NACIONAL DA INDÚSTRIA - CNI. Agendas Legislativas da Indústria - 1997 a 2006. Conselho de Assuntos Legislativos - CAL e Unidades de Assuntos Legislativos - COAL. Brasília.

DINIZ, E. Empresários e governo Lula: percepções e ação política entre 2002 e 2006. Texto apresentado no V Workshop Empresa, Empresários e Sociedade: o mundo empresarial e a questão social, PUCRS, Porto Alegre, 2006. Disponível em < http://www.fee.rs.gov. br/5workshop/pdf/mesa02_eli.pdf $>$. Acesso em março/2007.

. Empresário, democracia e desenvolvimento: tendências e desafios no limar do novo milênio. Trabalho apresentado no VIII Congresso Luso-Afro-Brasileiro, em Coimbra, 2004.

DINIZ, E. \& BOSCHI, R. Empresários, interesses e mercado: dilemas do desenvolvimento no Brasil. Belo Horizonte, Ed. UFMG, 2004.

FIGUEIREDO, A.C. \& LIMONGI, F. Executivo e legislativo na nova ordem constitucional. Rio de Janeiro: FGV, 1999.

FURLONG, S.R. Interest group influence on rule making. Administration \& Society, v. 29, n. 3, 1997. SAGE Journals Online. Disponível em: <http://intl-online.sagepub.com>. Acesso em jun./2007.

FURLONG, S.R. \& KERWIN, C.M. Interest group participation in rule making: a decade of change. Journal of Public Administration Research and Theory, v.15, n. 3, 2005. Disponível: < http://intl-online. sagepub.com > . Acesso em jun./2007.

HANSFORD, T.G. Lobbying strategies, venue selection, and organized interest involvement at the U.S. Supreme Court. American Politics Research, v. 32, n. 2, march 2004, p.170-197. Disponível em: < http:// www.sagepublications.com>. Acesso em jun./2007. 
HOJNACKI, M. \& KIMBALL, D.C. The who and how of organizations' lobbying strategies in Committee. The journal of politics, v. 61, n. 4, nov.1999, p.999-1024. Disponível em: <http://links.jstor.org>. Acesso em julho de 2007.

LEVI, M. A model, a method, and a map: rational choice in comparative and historical analysis. In: Mark Lichbach e Alan S. Zuckerman. Comparative politics: rationality, culture, and structure. Cambridge: Cambridge University Press, 1997.

MANCUSO, W.P. O lobby da indústria no congresso nacional: empresariado e política no Brasil contemporâneo. Dados - Revista de Ciências Sociais, Rio de Janeiro, v. 47, n. 3, 2004.

NORTH, D. Institution, institutional change and economic performance. New York: Cambridge University Press, 1990.

OLSON, M. A lógica da ação coletiva. São Paulo: USP, 1999.

SANTOS, F. \& ALMEIDA, A. Teoria informacional e a seleção de relatores na Câmara dos Deputados. Dados - Revista de Ciências Sociais, Rio de janeiro, v. 48, n. 4, 2005.

VINHA, V.G. O estado e as empresas ecologicamente comprometidas sob a ótica do neocorporativismo e do state-society synergy approach: o caso do setor de papel e celulose. Revista Arché Interdisciplinar, Rio de Janeiro, Ano VIII, n. 25, p. 13-46, 1999.

\begin{abstract}
Industrial entrepreneurs and political action regarding environmental norms for the Federal Legislature: correlating participation and influence.

In Brazil, political institutions that create environmental norms are targets of pressure in function of the restrictions that they impose to industrial business from environmental regulations. The study seeks to answer how the industrial business interest group participates and influences on the environmental policy design. The study shows that the new institutional context strengthened the corporative representation system, defined new forms of interaction between State and industrial businesses men and delineated a new articulation pattern within the policy system. This made the industrial business interest group an influential group in shaping the environmental policy. The study central questions are (a) how people that
\end{abstract}


act on behalf of industrial business men have access to policy instance and (b) to what extent are their influence. These questions are analyzed from the theory of interests group and the institutional approach. This theoretical framework is able to explain how the interest group has channels of access, participates and has power of influence taking into account the dynamics of the institutions that are targets of pressure.

Keywords: environmental regulation, entrepreneurial environmentalism, articulation of Interest, political pressure. 
